\title{
Francisco José Delich
}

Carlos Clavaguera ${ }^{1}$

Era la noche del viernes 20 de mayo, ya estaba en casa, y fue ahí cuando recibí la noticia del fallecimiento del Dr. Francisco José Delich. Como siempre ocurre cuando comunican estos sucesos, en ese momento, cuesta darse cuenta. A poco se va asimilando y allí sobrevienen un mundo de reacciones, emociones y recuerdos que te devuelven a la realidad de la triste novedad.

Con gran sentimiento, comenzaron a emerger los recuerdos de los momentos compartidos, pensé en todos los años en que lo conocí: algunos más intensos, otros a la distancia, pero siempre, de alguna manera estaba presente.

Recordé que la primera vez que escuché mencionar el nombre de Francisco Delich fue cuando se desempeñaba como Rector Normalizador de la Universidad de Buenos Aires. Había leído sobre su forma de entender la universidad mientras me encontraba cursando los últimos años de la carrera en la Facultad de Arquitectura y Urbanismo (FAU) e integraba la Franja Moraba RA. Agrupación que lo propuso como candidato a Rector de la Universidad Nacional de Córdoba por su trayectoria, ideas educativas innovadoras, formación intelectual, espíritu reformista y otras tantas cualidades, además de ser egresado de la Facultad de Derecho de la UNC, y haberse doctorado en Ciencias Sociales. Finalmente, tras una reñida contienda electoral, resultó elegido por la Asamblea Universitaria como Rector para el período 1989-1992.

A partir de ese momento -acababa de recibirme de arquitecto-, él ingreso de lleno a nuestra vida universitaria, de la que participábamos colaborando y brindando apoyo con las mismas fuerzas que manteníamos desde nuestros tiempos de estudiantes y militantes de la Franja. No solo comenzamos a compartir su gestión universitaria, sino momentos de camaradería donde nos mostró su faceta más personal, la del amigo con el

\footnotetext{
${ }^{1}$ Arquitecto. Centro de Estudios Avanzados de la Facultad de Ciencias Sociales de la Universidad Nacional de Córdoba (UNC).
} 
que disfrutábamos de la compañía mutua más allá del grupo político que integrábamos.

En 1992 siendo miembro del H. Consejo Directivo de la Facultad de Arquitectura y Urbanismo en representación del claustro de egresados, formé parte de la Asamblea Universitaria que lo eligió para su segundo mandato. Esto es algo que me llenó, y me llena, de satisfacción.

En agosto de ese mismo año, me convocó para trabajar en su Rectorado como Coordinador de Diagnóstico de Desarrollo Urbano con asiento en el Centro de Estudios Avanzados. Aquí, junto a un grupo de profesionales de varias disciplinas, desarrollamos una actividad extensionista para localidades del interior provincial y centros vecinales de la ciudad de Córdoba, labor que continuamos realizando hasta 1996.

Durante los dos períodos que fue Rector de la Universidad Nacional de Córdoba (1989-1995), en los que lo acompañamos en su gestión, la vida universitaria nos fue llevando a compartir no solo espacios de trabajo intensos y productivos sino también otros ambientes más relajados y tranquilos, fuera del ámbito de la Universidad y lejos de la toga rectoral, favorables para establecer un diálogo de amigos. Allí descubrimos la simpleza de su forma de ser, nos abrió su mundo más familiar, sus gustos por las cosas sencillas, su pasión por la «celeste» de Belgrano, sus vivencias de barrio Alberdi y su actividad partidaria en la Unión Cívica Radical.

El tiempo compartido fue mucho, y los lugares, variados, dentro o fuera de la UNC. Recuerdo las juntadas en Lado Bueno y las jornadas en el complejo de Vaquerías, para mencionar algunos de esos espacios en los que congeniábamos y amenizábamos el trabajo con la distracción. Tanto es así, que puedo afirmar que mi vida actual de familia se inició en uno de esos momentos, para ser exacto, el primero de mayo de 1992 en Vaquerías, y él lo festejó con mucho agrado, igual que el resto de mis amigos.

Concluido su rectorado, por distintas razones se distanció de la Universidad y del grupo que conformábamos. Se dedicó más a la actividad política, resultando electo Diputado Provincial por la UCR para el período 1997-2001. Durante ese lapso lo encontré en varias oportunidades en reuniones partidarias, en las que siempre demostró su aprecio, interesándose por conocer la situación en que estaban sus amigos de la Universidad.

Recuerdo que en un viaje a Buenos Aires me invitó a visitarlo en la Biblioteca Nacional de la que entonces era Director, y juntos recorrimos con una entretenida charla ese gran edificio emblemático diseñado por Clorindo Testa. 
Volví a verlo en 2002 en el Centro de Estudios Avanzados (CEA), institución creada por él en 1990, donde trabajamos durante un año en el proyecto de creación de un Doctorado en Ciencias Sociales. Que lamentablemente no prosperó.

A partir de allí, sus regresos al CEA no fueron muy asiduos, hasta el año 2007 en que fue designado Director del nuevo Doctorado en Estudios Sociales de América Latina (DESAL), además de comenzar a dirigir el postdoctorado en Ciencias Sociales (el primero en su nivel de América Latina). Desde ese momento contamos nuevamente con su presencia de manera continua, situación que pude aprovechar al máximo para conversar, intercambiar opiniones, escuchar sus análisis, volver a estrechar lazos y disfrutar nuevamente de su trato cordial, ameno y siempre atento.

Así llegamos a ese triste 20 de mayo de 2016, con la noticia que muy de repente y fuera de toda previsión nos tomó por sorpresa, debido a que Francisco Delich no había comentado de su dolencia en este ámbito de trabajo, su Universidad, su CEA. Que paradójicamente el año pasado cumplió sus primeros 25 años de vida y en cuyos festejos se hizo presente y brindó unas palabras.

En ese momento fue cuando pensé, qué «gran tipo» he tenido a mi lado estos 27 años de vida universitaria, con cualidades y virtudes aunadas, un intelectual con destacada trayectoria en ámbitos académicos, culturales, políticos y de gestión pública. Con reconocimiento tanto nacional como internacional, con títulos de Doctor Honoris Causa de las Universidades de San Carlos (Perú), Nottingham (Gran Bretaña) y Soka (Japón), escritor, y por qué no un pensador, un hombre íntegro, honesto, creativo, y sencillo, un ferviente correligionario, y un amigo.

Se extraña su presencia. Cuando concurría al CEA de manera habitual me acercaba al box del DESAL y conversábamos de temas de lo más variados: la Universidad (evidentemente), el Partido Radical, sus hijos y sus nietos, mi familia, los piratas de Belgrano, los amigos en común y tantos otros que amenizaban la charla, hasta que notábamos que se extendía demasiado y era necesario volver a la rutina del trabajo.

En una oportunidad, después de su regreso al CEA, le pregunté si recordaba que en una ocasión le había comentado mi hallazgo de una revista 7 Días de fines de la década del 60, la que contenía una entrevista a un «prometedor sociólogo» recién llegado de sus estudios de postgrado en Economía y Sociología en la École des Hautes Études de la Universidad de París... Le dije: «Bueno, es esta». Se la entregué. A continuación la hojeó. Miró la nota. Y respondió como era habitual en él, explayándose en 
comentarios de vivencias ocurridas entonces. «Carlitos, ha pasado tanto tiempo. No vayas a creer todo lo que dicen». Me devolvió la revista. Aún la tengo guardada. Con gran afecto. 